\title{
A comparison of hospital readmission rates between two general physicians with different outpatient review practices Hugh C Rayner*1, R Mark Temple ${ }^{1}$, Tim Marshall² and Dianne Clarke ${ }^{1}$
}

Address: ${ }^{1}$ Birmingham Heartlands and Solihull NHS Trust (Teaching), Birmingham, UK and ${ }^{2}$ University of Birmingham, Birmingham, UK

E-mail: Hugh C Rayner* - Raynerh@heartsol.wmids.nhs.uk; R Mark Temple - Templer@ heartsol.wmids.nhs.uk; Tim Marshall - T.Marshall@bham.ac.uk; Dianne Clarke - Clarked@heartsol.wmids.nhs.uk

${ }^{*}$ Corresponding author

Published: 25 June 2002

BMC Health Services Research 2002, 2:12
Received: 22 October 2001

Accepted: 25 June 2002

This article is available from: http://www.biomedcentral.com/I472-6963/2/12

(c) 2002 Rayner et al; licensee BioMed Central Ltd. Verbatim copying and redistribution of this article are permitted in any medium for any purpose, provided this notice is preserved along with the article's original URL.

\begin{abstract}
Background: There has been a relentless increase in emergency medical admissions in the UK over recent years. Many of these patients suffer with chronic conditions requiring continuing medical attention. We wished to determine whether conventional outpatient clinic follow up after discharge has any impact on the rate of readmission to hospital.

Methods: Two consultant general physicians with the same patient case-mix but markedly different outpatient follow-up practice were chosen. Of 1203 patients discharged, one consultant saw twice as many patients in the follow-up clinic than the other ( $\operatorname{Dr} A 9.8 \%$ v $\operatorname{Dr} B$ 19.6\%). The readmission rate in the twelve months following discharge was compared in a retrospective analysis of hospital activity data. Due to the specialisation of the admitting system, patients mainly had cardiovascular or cerebrovascular disease or had taken an overdose. Few had respiratory or infectious diseases. Outpatient follow-up was focussed on patients with cardiac disease.

Results: Risk of readmission increased significantly with age and length of stay of the original episode and was less for digestive system and musculo-skeletal disorders. $28.7 \%$ of patients discharged by $\operatorname{Dr} A$ and $31.5 \%$ of those discharged by $\operatorname{Dr} B$ were readmitted at least once. Relative readmission risk was not significantly different between the consultants and there was no difference in the length of stay of readmissions.

Conclusions: Increasing the proportion of patients with this age- and case-mix who are followed up in a hospital general medical outpatient clinic is unlikely to reduce the demand for acute hospital beds.
\end{abstract}

\section{Background}

The number of emergency general medical admissions continues to grow relentlessly, many patients having repeated admissions due to exacerbations of chronic disease. The rate of readmission is sometimes used as an indicator of discharge practice performance and targets to reduce this rate have been set in the UK National Health Service [1].

In the United Kingdom National Health Service, there are three common patterns of follow up care following an emergency general medical admission: 1) in the community, by the patient's general practitioner (primary care 
physician), 2) at a hospital outpatient clinic provided by the general physician who supervised the inpatient episode and 3) at a hospital specialist clinic appropriate to the patient's condition.

One potential method for reducing the rate of readmissions is more frequent outpatient clinic review of patients after discharge. However, there is limited evidence regarding the effectiveness of the current practice of outpatient review following discharge from hospital in reducing readmissions.

We took the opportunity of studying two physician colleagues with similar clinical practice who differed in their outpatient follow up practices. Following discharge, one reviewed twice as many patients in his personal general medical outpatient clinic than the other. The aim of this study was to identify any difference in the rate of readmission and the length of stay of readmissions associated with these different review practices.

\section{Methods}

The emergency take at Birmingham Heartlands Hospital is sub-specialised, patients with acute myocardial infarction, respiratory conditions and infectious diseases being admitted directly under the appropriate specialist team. All other patients come under the care of the general physician of the day who practices general medicine separately from his or her speciality interest. The two physicians were general physicians at Birmingham Heartlands Hospital and had been appointed in 1993 and 1995. Both had an equal share of the general medical admitting rota and so received an equivalent random sample of the total emergency medicine admissions over the course of a 12 month period. Both had a special interest in renal medicine but this study only relates to their general medical practice.

Inpatient data was taken retrospectively by DC from the routinely collected hospital activity computer database, which records all inpatient episodes. Coding was performed by professional coders using diagnoses provided by clinicians at the time of discharge. All patients who had been admitted as an emergency to General Medicine, managed by Dr Rayner or Dr Temple and subsequently discharged by them between April 1997 and March 1998 were included in the analysis.

Factors associated with readmission were explored using multiple logistic regression analysis with independent variables of age, sex, length of stay of original admission episode, HRG coding and discharging consultant. Length of stay was divided into three categories, $<3$ days, 3-7 days and $>7$ days. Since the decision to review the patient in the clinic would be affected by the HRG code and length of stay of the original admission, as well as the consultant discharging the patient, whether the patient was reviewed in the clinic was not included as an independent variable.

\section{Results}

A total of 1366 inpatient episodes were collected from 1289 patients, 70 patients having more than one episode. In 1280 discharge episodes (1203 patients) the patient left the hospital alive and so outpatient follow up was possible. This cohort was used for subsequent analysis.

Because of the specialisation in the admitting arrangements relatively few patients were coded to respiratory system (HRG3 D) (table 1). There was no significant interaction between consultant and HRG code in the logistic regression analysis, confirming that the case-mix was not significant different between the two consultants. There was similarly no difference in sex ( $\mathrm{Dr} A=51.7 \%$ male, $\mathrm{Dr}$ $\mathrm{B}=51.2 \%$ male) or the age distribution (Figure 1).

The number of patients offered and either attending or not attending a first outpatient appointment within 90 days of discharge is shown in Table 2. Dr B saw twice as many patients as Dr A, 124 (19.6\% of discharges) versus $63(9.8 \%)$. The timing of outpatient clinics of those patients reviewed following discharge is shown in Figure 2. Dr A reviewed patients slightly earlier than Dr B. The age and HRG distributions of patients seen were very similar, $66.3 \%$ being for the cardiac HRG chapter. Hence, Dr B saw twice as many patients coded in the cardiac group (HRG3 Chapter E) as Dr A, 84 patients (30\% of possible follow ups) versus 40 (15.8\%). Dr B also had a higher subsequent appointment rate (58.6\% versus $32.1 \%$ ), giving an average number of appointments per patient of 1.59 and 1.32 respectively.

Following discharge, a number of patients were referred to other specialist clinics rather than being followed up in the general medical clinic of the admitting consultant. Similar numbers were referred to other clinics by each consultant, 177 (25\%) by Dr A and 156 (23\%) by Dr B, with a similar spread of specialities. There was no difference in the referral rate to cardiology clinics (33 patients from each consultant).

\section{Re-admission rates}

From the cohort of 1203 patients discharged, 411 patients were readmitted to the Trust as an emergency under any speciality in the twelve months after discharge. $28.7 \%$ of patients discharged by Dr A and $31.5 \%$ of those discharged by Dr B were readmitted at least once. Many patients had more than one re-admission and the total number of episodes generated by these 411 patients was 800 (Table 3), Dr A's cohort generating 388 and Dr B's 412 episodes. 
Table I: HRG3 Chapter Codes for patients discharged by the two consultants.

\begin{tabular}{|c|c|c|c|c|c|}
\hline \multirow[b]{2}{*}{ HRG3 } & \multirow[b]{2}{*}{ Description } & \multicolumn{2}{|c|}{$\operatorname{Dr} \mathbf{A}$} & \multicolumn{2}{|c|}{ Dr B } \\
\hline & & Discharges & $\%$ & Discharges & $\%$ \\
\hline$A$ & Nervous System & 58 & 9.0 & 66 & 10.4 \\
\hline B & Eyes and Periorbita & 3 & 0.5 & 2 & 0.3 \\
\hline $\mathrm{C}$ & Mouth, Head, Neck and Ears & 5 & 0.8 & 5 & 0.8 \\
\hline $\mathrm{D}$ & Respiratory System & 23 & 3.6 & 26 & 4.1 \\
\hline $\mathrm{E}$ & $\begin{array}{l}\text { Cardiac Surgery \& Primary Cardiac } \\
\text { Condition }\end{array}$ & 253 & 39.2 & 280 & 44.2 \\
\hline $\mathrm{F}$ & Digestive System & 58 & 9.0 & 39 & 6.2 \\
\hline G & Hepato-biliary \& Pancreatic System & 5 & 0.8 & 9 & 1.4 \\
\hline $\mathrm{H}$ & Musculoskeletal System & 44 & 6.8 & 31 & 4.9 \\
\hline J & Skin, Breast \& Burns & 9 & 1.4 & 3 & 0.5 \\
\hline $\mathrm{K}$ & Endocrine \& Metabolic System & 15 & 2.3 & 21 & 3.3 \\
\hline $\mathrm{L}$ & $\begin{array}{l}\text { Urinary Tract \& Male Reproductive } \\
\text { System }\end{array}$ & 12 & 1.9 & 7 & 1.1 \\
\hline M & Female Reproductive System & $\mathbf{0}$ & 0.0 & $\mathbf{0}$ & 0.0 \\
\hline $\mathrm{N}$ & Obstetrics \& Neonatal Care & 0 & 0.0 & 0 & 0.0 \\
\hline$P$ & Diseases of Childhood & 2 & 0.3 & 2 & 0.3 \\
\hline $\mathrm{Q}$ & Vascular System & 3 & 0.5 & 4 & 0.6 \\
\hline $\mathrm{R}$ & $\begin{array}{l}\text { Spinal Surgery \& Primary Spinal } \\
\text { Conditions }\end{array}$ & 4 & 0.6 & 2 & 0.3 \\
\hline S & $\begin{array}{l}\text { Haematology, Infectious Disease, } \\
\text { Poisoning \& Non-specific groupings }\end{array}$ & $\mathbf{I I}$ & 17.2 & 104 & 16.4 \\
\hline $\mathrm{T}$ & Mental Health & 22 & 3.4 & 13 & 2.1 \\
\hline \multirow[t]{2}{*}{$u$} & Undefined Groups & 19 & 2.9 & 20 & 3.2 \\
\hline & Totals & 646 & 100.0 & 634 & 100.0 \\
\hline
\end{tabular}

The age distribution for re-admissions was more skewed to the elderly than the initial cohort (Figure 3 ). The greatest rate of re-admission occurred in the first 6 weeks after discharge and continued steadily over the subsequent 11 months (Figure 4).

The HRG coding for the re-admission episode closely matched that for the initial admission (see Additional file: Table 4). Cardiac disorders (HRG3 Chapter E) was the dominant group. 76 (28.9\%) of the 263 patients in this group discharged by Dr A (38\% of the discharge cohort), were re-admitted at least once, generating 143 episodes (36.9\% of readmission episodes). 64 (22.1\%) of the 289 patients in this group discharged by Dr B (43\% of the discharge cohort), were re-admitted at least once, generating 160 episodes (38.8\% of re-admission episodes). Cardiac disorders (HRG3 Chapter E) made up $66 \%$ of patients followed up in outpatients

A similar proportion of the patients who attended the follow-up general medical clinics for each consultant were readmitted within the 12 months following discharge, 6 of 63 for Dr A (10\%) and 11 of 124 for Dr B (9\%).
Variables independently associated with readmission were increasing age (expressed in units of 10 years), particular HRG codes (both Digestive system, and Musculoskeletal system, in comparison with all other HRG's - see table 5), and increasing length of stay (LoS) of the original inpatient episode. The discharging consultant was not a "risk factor" for readmission, and there was no interaction between consultant and HRG code.

\section{Length of stay}

Patients who were subsequently readmitted had a longer original length of stay than those not readmitted (mean $4.9 \vee 3.6$ days, median $3 \vee 2$ days). The length of the readmission episodes was much longer and did not differ between the consultants (mean $8.1 \mathrm{v} 8.1$ days, median $4 \mathrm{v}$ 4 days).

\section{Discussion}

This observational study compares two consultant physicians whose general medical practice, due to the specialist admissions arrangements for respiratory or infectious diseases, focussed on cardiovascular and cerebrovascular disease and deliberate self-harm. About one-third of patients were readmitted at least once over the twelve month peri- 


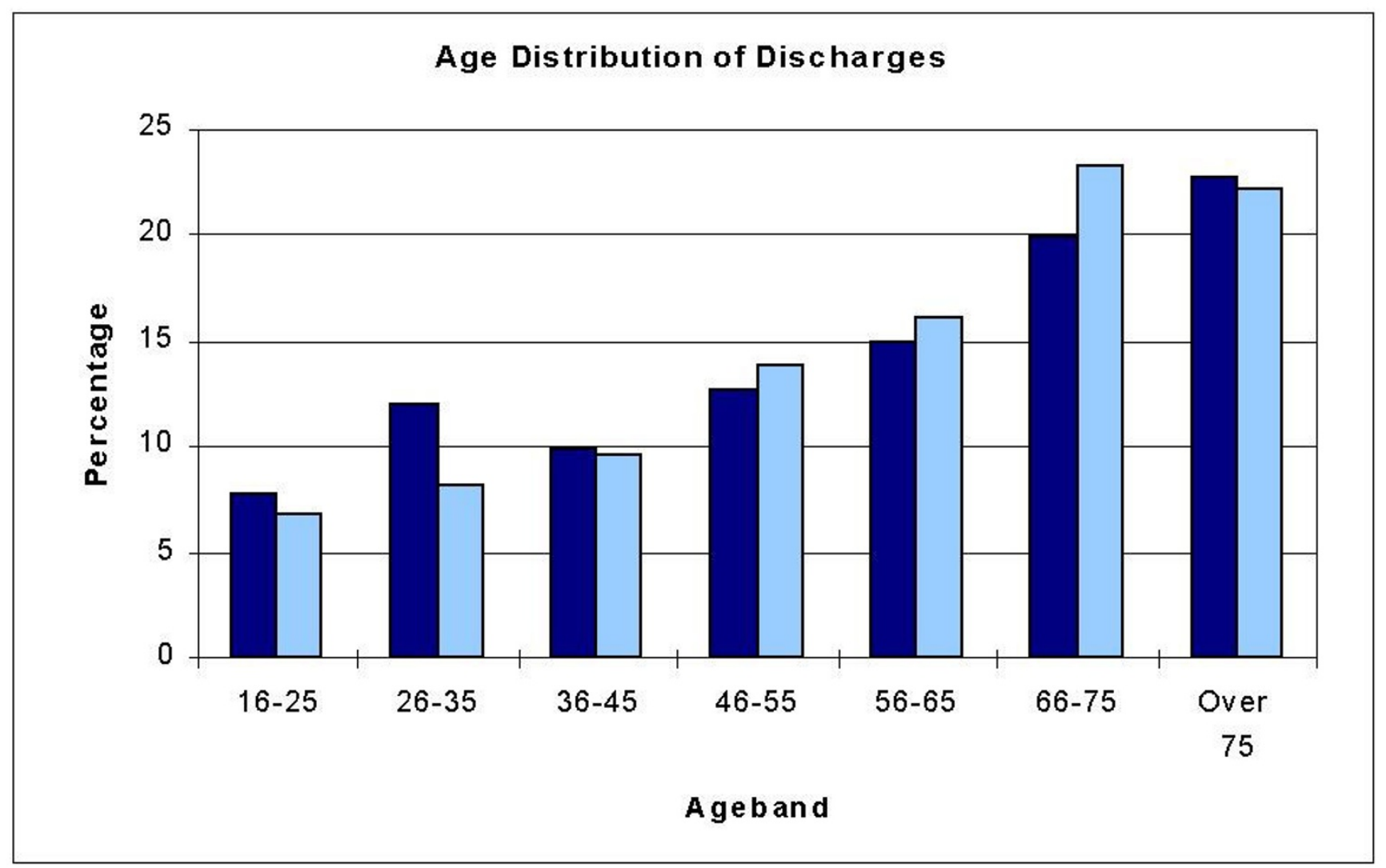

Figure I

Age distribution for patients discharged by each consultant

Table 2: Number patients attending and not attending (in brackets) the first follow-up appointment within 90 days of discharge.

\begin{tabular}{|c|c|c|c|c|c|c|c|c|c|c|c|c|c|c|c|c|}
\hline \multirow{2}{*}{$\begin{array}{l}\text { Patient age } \\
\text { (yrs) } \\
\text { Dr A }\end{array}$} & \multicolumn{2}{|c|}{$16-25$} & \multicolumn{2}{|c|}{$26-35$} & \multicolumn{2}{|c|}{$36-45$} & \multicolumn{2}{|c|}{$46-55$} & \multicolumn{2}{|c|}{$56-65$} & \multicolumn{2}{|c|}{$66-75$} & \multicolumn{2}{|c|}{ Over 75} & \multicolumn{2}{|c|}{ Total attending } \\
\hline & 2 & (0) & 5 & (I) & 5 & (3) & 4 & (2) & 14 & (5) & 20 & (2) & 13 & (5) & 63 & $9.8 \%$ \\
\hline Dr B & 1 & (I) & 1 & (0) & 10 & (3) & 19 & (5) & 23 & (4) & 43 & (6) & 27 & (2) & 124 & $19.6 \%$ \\
\hline
\end{tabular}

od following discharge and the total number of readmis-

discharges.

sion episodes equalled about half of the number of 


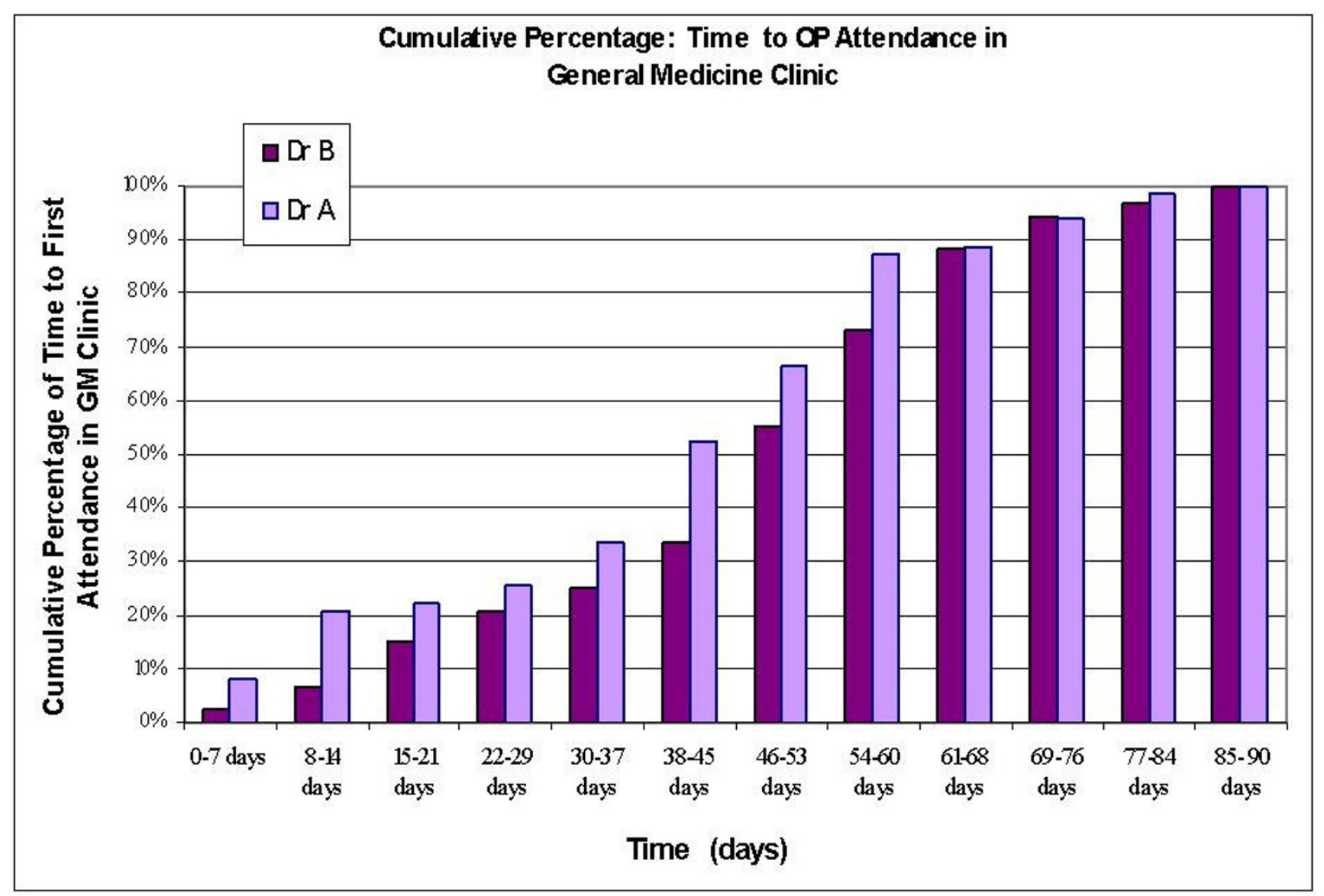

Figure 2

Cumulative percentage of patients attending first general medical out-patient review clinic with time after discharge for each consultant.

Table 3: Readmission rates following discharge episode.

\begin{tabular}{|c|c|c|c|c|c|c|c|c|c|c|c|c|c|}
\hline & \multirow{2}{*}{$\begin{array}{l}\text { Single Epi- } \\
\text { sodes }\end{array}$} & \multicolumn{8}{|c|}{ Number of Emergency Re-admission episodes } & \multirow[b]{2}{*}{9} & \multirow[b]{2}{*}{15} & \multirow{2}{*}{$\begin{array}{l}\text { Re-adm Epi- } \\
\text { sodes }\end{array}$} & \multirow{2}{*}{$\begin{array}{c}\text { Overall } \\
\text { Total }\end{array}$} \\
\hline & & $\mathbf{I}$ & 2 & 3 & 4 & 5 & 6 & 7 & 8 & & & & \\
\hline No. of Patients & 792 & 230 & 89 & $4 I$ & 23 & 12 & 7 & 5 & 2 & I & $I$ & $4 I I$ & 1203 \\
\hline No. of Re-adm Epi & 0 & 230 & $\begin{array}{c}17 \\
8\end{array}$ & $\begin{array}{c}12 \\
3\end{array}$ & 92 & 60 & 42 & 35 & 16 & 9 & 15 & 800 & - \\
\hline
\end{tabular}




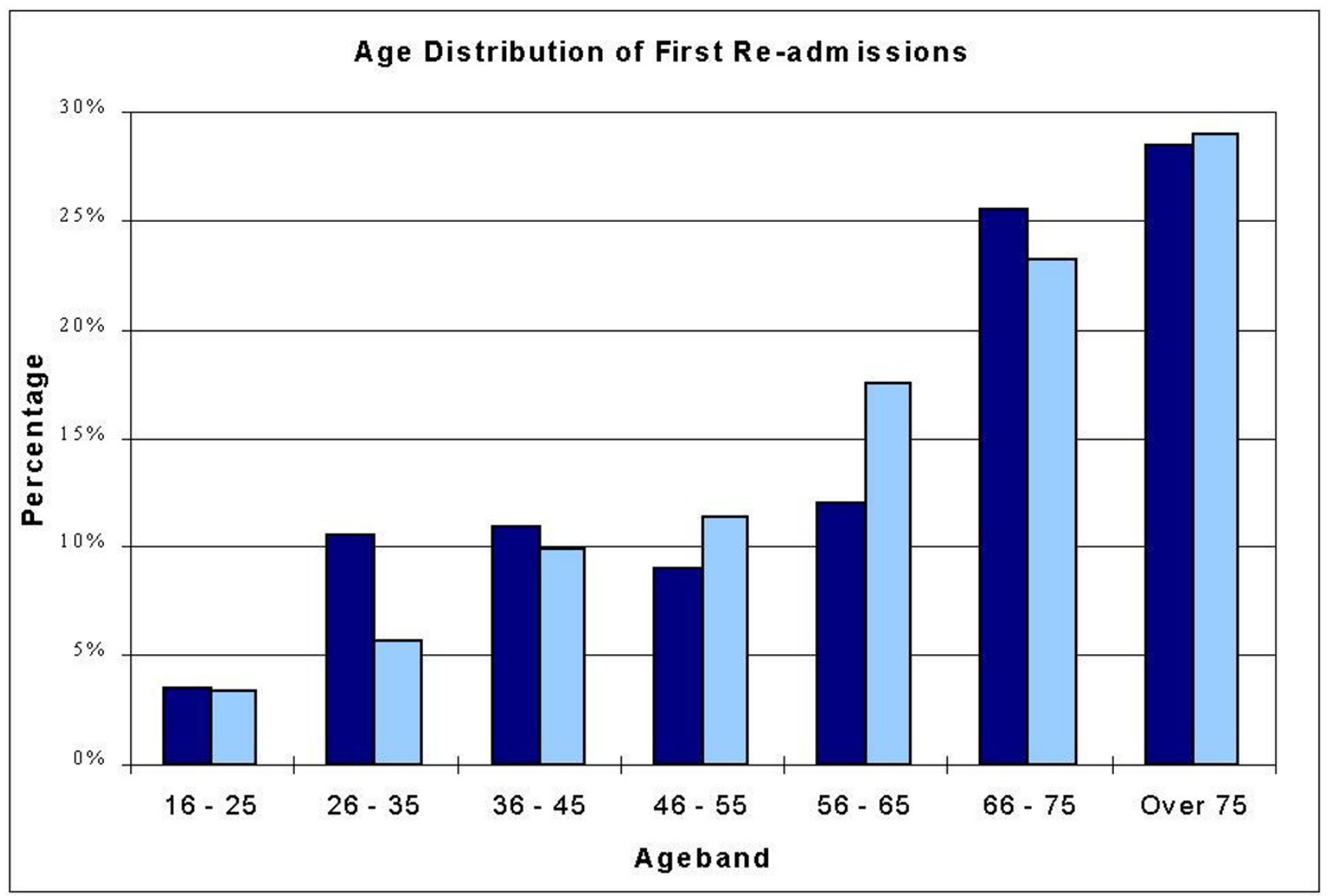

Figure 3

Age distribution for patients readmitted following discharge by each consultant.

The risk of readmission was greater in older patients and in those with a longer initial inpatient stay. A longer length of stay may indicate more severe disease or less adequate social circumstances. The risk was less in those with digestive and musculo-skeletal conditions (HRG3 Chapters $\mathrm{F}$ and $\mathrm{H}$ ), which would have included conditions that are less likely to recur, such as gastro-intestinal bleeding and musculoskeletal pain. For the middle length of stay group (3-7 days) and digestive conditions, p-values are marginally non-significant; but the former is part of a clear trend with increasing length of stay, and the latter is so sharply distinguished from any other risks in specific HRG's that it was included.

The rate of readmission for both physicians was high. However, similar rates of readmission have been reported from the USA [2] and Australia [3] in similar patient groups. The risk of readmission in these studies was also associated with patient characteristics such as age, co morbidity, depression and previous readmission events $[4,5]$ rather than the quality of patient care [4].

As both consultants reviewed a proportion of patients in the outpatient clinic, it is not possible to exclude totally an effect of general medical clinic review on the rate of readmissions. Furthermore, only one outcome of treatment, readmission, has been looked at in this study and we have no way of comparing the quality of patient care or patient satisfaction.

The rate of readmission was highest in the first six weeks after discharge. Approximately 50\% of follow-up appointments were made for more than six weeks after discharge and hence these could not be expected to affect the early readmission rate. It would be interesting to study the impact of earlier outpatient review on readmission rates. 


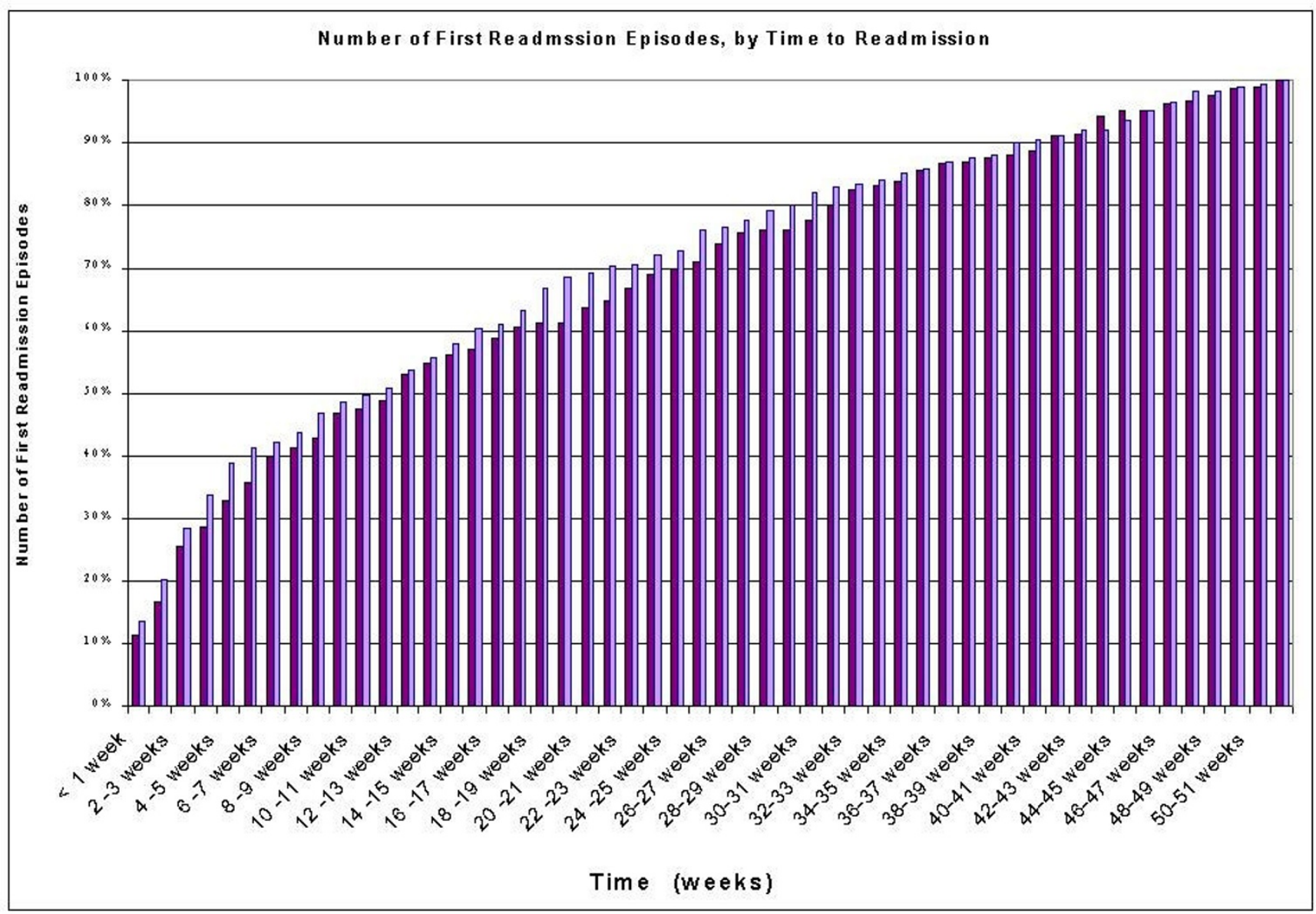

Figure 4

Cumulative growth of readmissions during 12 month period after discharge by each consultant.

Table 5: Variables independently associated with readmission from multiple logistic regression analysis. Length of stay for categories 3-7 days and $>7$ days was compared to $<3$ days.

\begin{tabular}{|c|c|c|c|c|c|}
\hline Variable & Coefficient & Std. Error & p-value & Odds Ratio & $95 \% \mathrm{Cl}$ \\
\hline Age (per 10 years) & 0.181 & 0.0344 & 0.0001 & 1.2 & $1.12-1.28$ \\
\hline Length of stay $3-7$ days & 0.27 & 0.144 & 0.061 & 1.31 & $0.99-1.74$ \\
\hline Length of stay $>7$ days & 0.388 & 0.189 & 0.041 & 1.47 & $1.02-2.14$ \\
\hline Digestive system & -0.45 & 0.248 & 0.069 & 0.64 & $0.39-1.04$ \\
\hline Musculoskeletal system & -0.95 & 0.33 & 0.004 & 0.39 & $0.20-0.74$ \\
\hline
\end{tabular}

This study compared two physicians with different thresholds for offering general medical outpatient clinic review following discharge. Although carried out by different consultants, the clinics were otherwise run in a similar and conventional way. It did not compare different types of outpatient clinic, which may be more effective than the conventional follow up clinic. Others have found similar difficulty in reducing the rate of readmission, either by in- 
volving a general practitioner in the discharge process [6] or running a nurse-led heart failure clinic [7].

More promising results have been reported in two studies of intensive intervention in the patients' home following admission for stroke [8], in which physician or physiotherapist visits reduced readmission rates, and for heart failure [9], in which visits by a cardiac nurse had a similar effect.

\section{Conclusions}

One can conclude that a practice of following up a larger proportion of patients with this age- and case-mix in the general medical outpatient clinic does not reduce the requirements for inpatient acute medical beds. These results would not support an increase in the use of general medical review clinics, of the type described in this study, in an attempt to control the growth in emergency admissions.

\section{Competing interests}

None declared.

\section{Authors' contributions}

HCR conceived the study and wrote the manuscript. RMT participated in the design of the study and writing of the manuscript. TM performed the statistical analysis. DC performed the data extraction and analysis.

All authors read and approved the final manuscript.

\section{Additional material}

\section{Additional file (Table 4)}

Table 4: HRG Chapter of the initial and re-admission episode. Click here for file

[http://www.biomedcentral.com/content/supplementary/14726963-2-12-S1.xls]

\section{References}

I. High Level Performance Indicator 6 iv Emergency admissions of older people. [http://www.doh.gov.uk/nhsperformanceindicators/hlpi2000/h I I37s.html]

2. Krumholz HM, Chen YT, Wang Y, Vaccarino V, Radford MJ, Horwitz $\mathrm{RI}$ : Predictors of readmission among elderly survivors of admission with heart failure. Am Heart J 2000, I39:72-7

3. Heller RF, Fisher JD, D'Este CA, Lim LL, Dobson AJ, Porter R: Death and readmission in the year after hospital admission with cardiovascular disease: the Hunter Area Heart and Stroke Register. Med J Aust. 2000, I 72:26I-5

4. Kossovsky MP, Sarasin FP, Perneger TV, Chopard P, Sigaud P, Gaspoz $\mathrm{J}$ : Unplanned readmissions of patients with congestive heart failure: do they reflect in-hospital quality of care or patient characteristics? Am J Med 2000, 109:386-90

5. Marcantonio ER, McKean S, Goldfinger M, Kleefield S, Yurkofsky M, Brennan TA: Factors associated with unplanned hospital readmission among patients 65 years of age and older in a Medicare managed care plan. Am J Med 1999, 107:13-7
6. Mclnnes E, Mira M, Atkin N, Kennedy P, Cullen J: Can GP input into discharge planning result in better outcomes for the frail aged: results from a randomised controlled trial. Fam Pract 1999, 16:289-93

7. Cline CM, Israelsson BY, Willenheimer RB, Broms K, Erhardt LR: Cost effective management programme for heart failure reduces hospitalisation. Heart 1998, 80:442-6

8. Andersen HE, Schultz-Larsen K, Kreiner S, Forchhammer BH, Eriksen $\mathrm{K}$, Brown A: Can readmission after stroke be prevented? Results of a randomised clinical study: a post discharge followup service for stroke survivors. Stroke 2000, 3 I:1038-45

9. Stewart S, Marley JE, Horowitz JD: Effects of a multidisciplinary, home-based intervention on unplanned readmissions and survival among patients with chronic congestive heart failure: a randomised controlled study. Lancet 1999, 354:1077-83

\section{Pre-publication history}

The pre-publication history for this paper can be accessed here:

http://www.biomedcentral.com/1472-6963/2/12/prepub

\footnotetext{
Publish with BioMed Central and every scientist can read your work free of charge

"BioMedcentral will be the most significant development for disseminating the results of biomedical research in our lifetime." Paul Nurse, Director-General, Imperial Cancer Research Fund

Publish with BMC and your research papers will be:

- available free of charge to the entire biomedical community

- peer reviewed and published immediately upon acceptance

- cited in PubMed and archived on PubMed Central

- yours - you keep the copyright

Submit your manuscript here: BioMedcentral.com http://www.biomedcentral.com/manuscript/ 